science, Evelyn Fox Keller. Keller suggested there may be a style of doing science that made it more congenial to male than female practitioners. Sokal acknowledges her excellent credentials as a scientist: "[Keller] is a different can of worms entirely." But he concludes from her reference to "the values articulated by early modern scientists" that she "implies that the issue is one of ethics, rather than of epistemology", missing the point that epistemology is not always so easily disentangled from values. He calls her association of science with the mastery and control of nature "a gross exaggeration" on the grounds that early Newtonian mechanics applied to astronomical phenomena "over which we have no control whatsoever”. He rejects Keller's speculation that a different style of doing science might result in a different science, because it "has no meaning except insofar as one can imagine that a different ideology might have led (in an imaginary counterfactual world) to a different course of scientific development". But Keller's well-known biography of the biologist Barbara McClintock is, in part, an exploration of this proposition in the real factual world.

Sokal also takes on Keller's essay "Cognitive repression in contemporary physics", a tour de force that invokes Jean Piaget's views of cognitive development to shed a different light on difficulties in the interpretation of quantum mechanics. In 1991, the American Journal of Physics declared the essay to be one of their six memorable papers of 1979. Overlooking Keller's wit, her fresh perspective and the fact that the paper was published nearly 30 years ago, before the current burst of interest in foundations of quantum mechanics, Sokal brusquely dismisses it as "exceedingly meager", with views that are neither new nor insightful.

Admittedly, Plotnitsky and Keller are two of Sokal's more formidable targets. And I should note that elsewhere in the book he is just as critical of those for whom he has sympathy as he is of those he finds - and I often agree - irredeemably foolish. He has an admirable passion for clarity of thought, and is commendably opposed to those who would pass off nonsense as profundity, whether they be commentators on science, spokesmen for religion, or the governments of nations. But Sokal's unwillingness to expand his frame of reference to accommodate legitimately different points of view undermines his effectiveness as a scourge of genuine rubbish.

I would like to think that we are not only beyond Sokal's hoax, but beyond the science wars themselves. This book might be a small step backwards.

N. David Mermin is Horace White Professor of Physics Emeritus at Cornell University, Ithaca, New York 14853-2501, USA. His latest book is Quantum Computer Science: An Introduction.

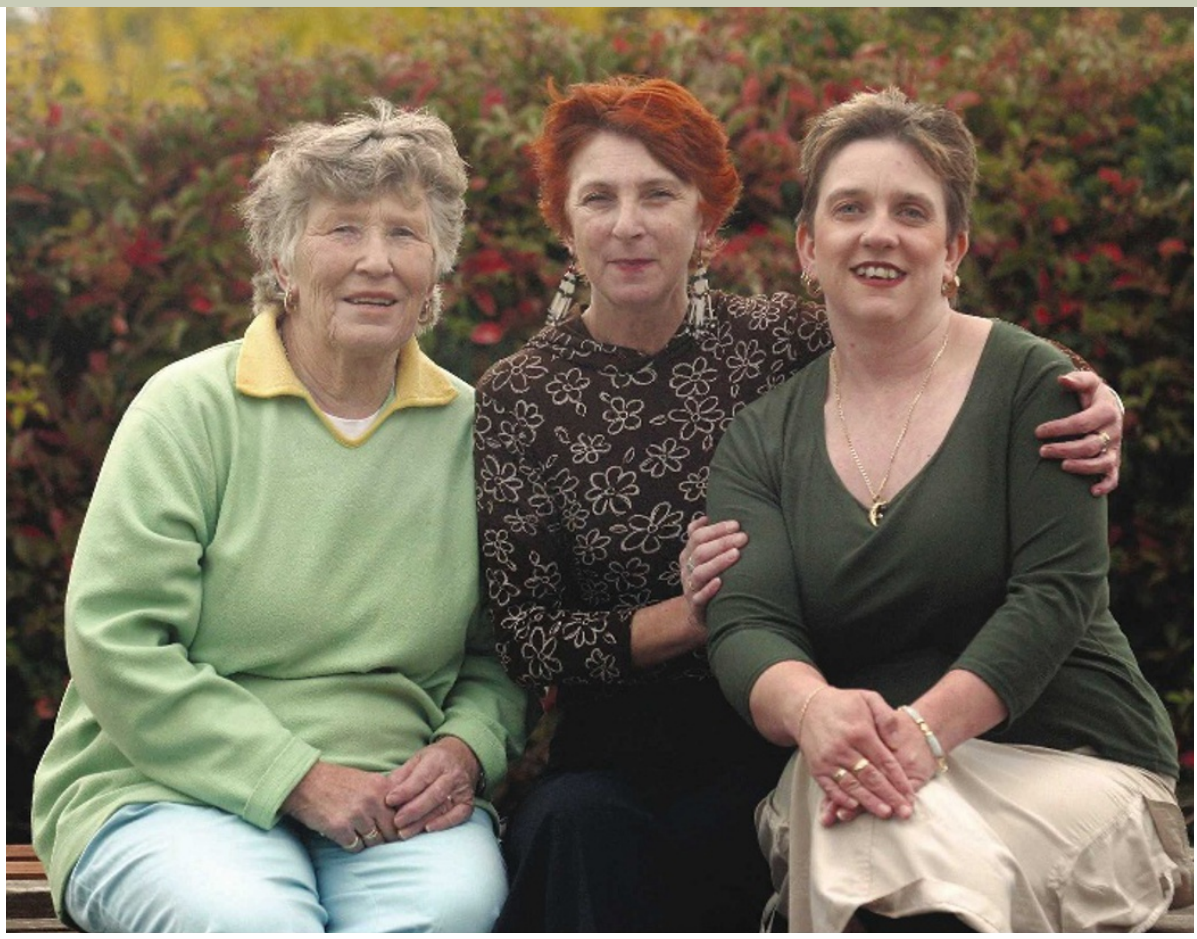

Three women in this family had breast cancer. Would they have been helped by a genetic diagnosis?

\title{
To know or not to know?
}

\section{Blood Matters: From Inherited Illness to \\ Designer Babies, How the World and I Found Ourselves in the Future of the Gene by Masha Gessen \\ Harcourt: 2008. 321 pp. $\$ 25.00$}

In 2004, journalist Masha Gessen published a personal account in the online magazine Slate of an increasingly common modern medical dilemma: how to respond to genetic diagnoses that offer both too much and not enough information. Gessen, a 37-year-old with a mutant form of the BRCA1 gene that is associated with an increased risk of breast cancer, promised to announce in the next issue whether she would undergo preventative surgery to remove her breasts and her ovaries to reduce her chances of developing cancer. Her book Blood Matters, now published four years on, explores the difficulties this decision involved.

Gessen encountered similar issues to those described in an earlier first-person narrative of genetic diagnosis, Mapping Fate by Alice Wexler (University of California Press, 1995). Wexler chronicled her experience of living in a family affected by Huntington's disease in the wake of the 1983 discovery of a genetic marker for the condition. She had a frontrow seat from which to produce an account of what it means to have one's fate mapped genetically: her mother died from Huntington's, her sister is one of the leading scientists who helped to find the Huntington's gene, and the research was partly funded by the Hereditary Disease Foundation established by their father. At the centre of Wexler's narrative lies a powerful lesson about the burdens of genetic knowledge. Paradoxically, the difference between abstract genetic information and real personal experience could be described as a knowledge gap. For the Wexlers, this gap was illustrated by the fact that, having found the gene and developed the test, neither sister was prepared to take it.

'To know or not to know' has thus become an added dimension of inherited pathology, creating new kinds of bonds and conflicts over the meanings of inherited genetic substance, among family members and unrelated people who share the same condition. This ambivalence is created by the very means intended to alleviate the burden of suffering to begin with - the production of detailed and accurate knowledge of how genes work. As in prenatal testing, the surfeit of explicit, readily accessible and sophisticated technical and scientific knowledge can make decisions that are based on genetic information more, rather than less, difficult.

Gessen's exploration of her own genetic inheritance, and her world tour of genetic research facilities and hospital clinics, highlight the dilemma of genetic decision-making more vividly than any such narrative to date. She comes to realize that the frontier of genetic medicine for her condition is "essentially surgical". She moves beyond weighing up the pros and cons to investigating the paradigms that shape genetic research, taking the reader on a breakneck tour of medical, biological, statistical, psychological and economic perspectives on genes, genetic risk 
and genetic disease. These snapshots produce a very contemporary form of autobiography - the autogenography, perhaps.

What she learns affects her ideas about herself and her children. From an apartment window in Moscow, she watches her adopted 9-year-old son drinking beer with a stranger in a park and reflects on the "dangerous business" of applying theories of genetic drift to humans when so much of how we are shaped is environmental. Is her son drawn to alcohol consumption from an early age by imitation or by genetic orientation? Like many commentators on the new genetics, Gessen is struck by the proliferation of genetic explanations in everyday life. She coins the term 'biobabble', after psychobabble, to describe how the gene is overused as a justification, such as when "midcareer professionals start explaining to potential partners that they had never formed an intimate relationship because of this or that polymorphism".

Despite its futuristic subtitle, and the novelty of increasing 'genetic choice' as a result of developments in gene testing, the somewhat unexpected lesson from Gessen's book is that the difficulties associated with genetic futures are not so new. They are being solved with the same combination of heart and mind that is one of the defining characteristics of being human, she finds. An unfortunate absence in Gessen's account is the scholarly contribution from social science or social psychology, such as in Theresa Marteau's and Martin Richards's landmark book The Troubled Helix (Cambridge University Press, 1999), which also illustrates this point. Here, and in the wide literature providing qualitative analysis of the genetic knowledge gap that separates abstract scientific facts from actual human experience, Gessen would find that the active and engaged community she describes in Blood Matters is even larger than she thinks.

Sarah Franklin is associate director of the BIOS Centre at the London School of Economics and Political Science, Houghton Street, London WC2A $2 \mathrm{AE}, \mathrm{UK}$. She is author of Born and Made: An Ethnography of Preimplantation Genetic Diagnosis.

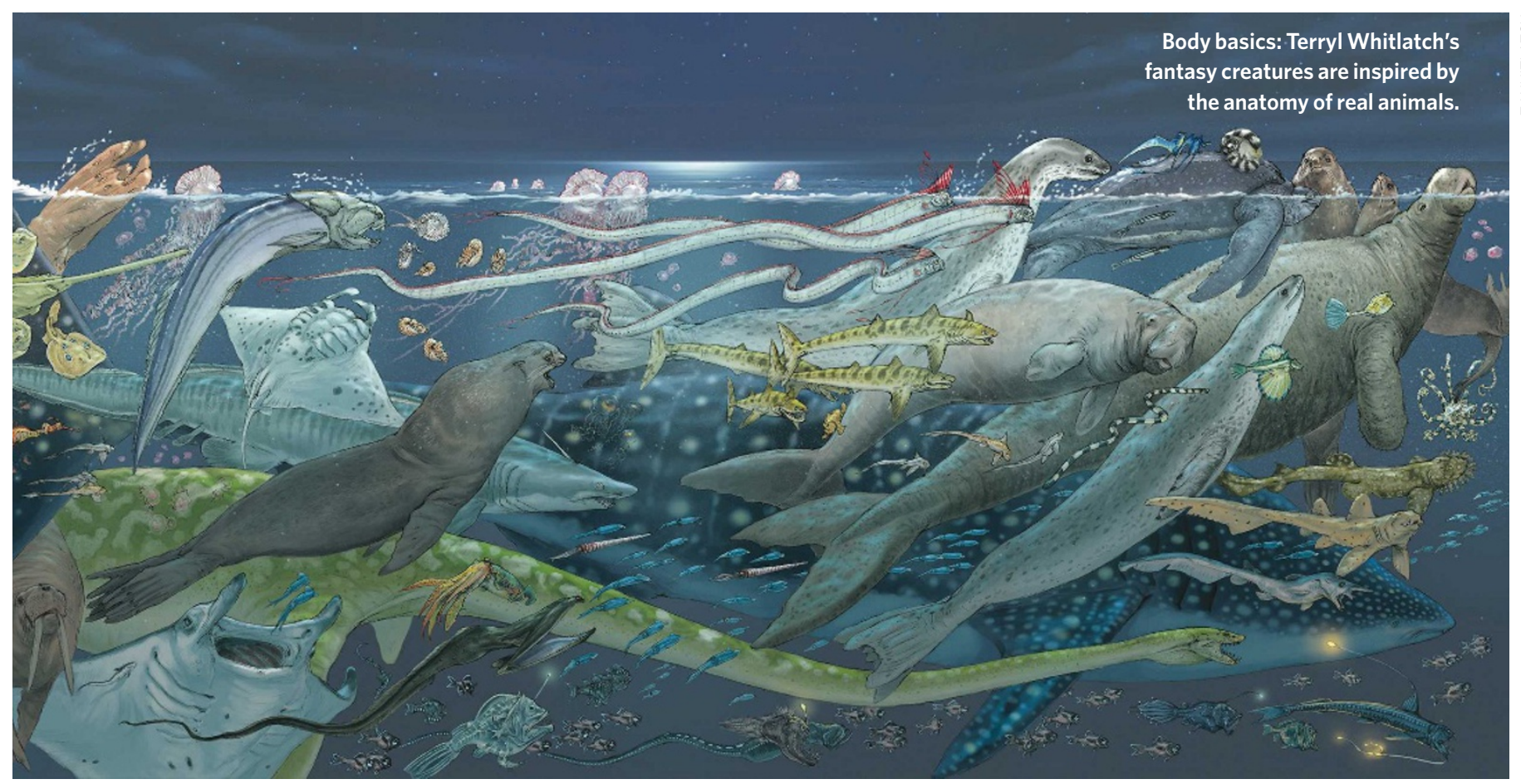

\section{Science artists draw together}

\author{
Annual Meeting of the Guild of Natural \\ Science Illustrators \\ Ithaca College, Ithaca, New York \\ 20-26 July. See www.gnsi.org
}

Science illustrators are in demand. Artists create images for books, posters and museum displays. In the film industry, talented concept artists design animals and fantasy creatures.

Forty years ago, the first meeting of the Guild of Natural Science Illustrators at the Smithsonian Institution, Washington DC, drew only a handful of local participants. The guild now has almost 1,000 members and, next week, hundreds will converge on Ithaca, New York, for the 2008 conference. Through workshops, lectures and field trips, "traditional artists using pencil, crowquill pens, and watercolour will come together with those on the edge of the latest computer software doing reconstructions and 3D animations", says Gretchen Halpert, the guild's president.

Terryl Whitlatch, a speaker at this year's conference, used her zoology training to design the monkeys and zebras for the 1995 fantasy film Jumanji. Her initial images were based on realistic skeletal, muscle and surface anatomy features that were then transformed into the three-dimensional computer-generated images seen in the film.

Whitlatch went on to invent alien creatures for the 1999 film Star Wars Episode I: The Phantom Menace. "I took ideas from animals and incorporated them into the world of fantasy art," she says. "I make sure the anatomy of a creature is matched with its environment to make it believable." The character of Jar Jar Binks, which was almost entirely computer generated for the film, was based on Whitlatch's combination of the duck-billed dinosaur, or hadrosaur, a frog, a parrot fish for skin patterns and markings, and an emu for the character's walk and stance.

Whitlatch creates her art with traditional techniques, then scans the artwork and enhances it 